\title{
Readings in Welfare Economics
}




\section{Readings in Welfare Economics}

a selection of papers

from the Review of Economic Studies

edited by

M. J. FARRELL

Macmillan Education 
(C) Economic Study Society 1973

All rights reserved. No part of this publication may be reproduced or transmitted, in any form or by any means, without permission.

First published 1973 by

THE MACMILLAN PRESS LTD

London and Basingstoke Associated companies in New York Toronto Dublin Melbourne Johannesburg and Madras

ISBN 978-0-333-10302-9 ISBN 978-1-349-15492-0 (eBook) DOI 10.1007/978-1-349-15492-0

Library of Congress catalog card no. 72-82152

The paperback edition of this book is sold subject to the condition that it shall not, by way of trade or otherwise, be lent, resold, hired out, or otherwise circulated without the publisher's prior consent, in any form of binding or cover other than that in which it is published and without a similar condition including this condition being imposed on the subsequent purchaser. 


\section{Contents}

Introduction M.J. Farrell

1. The Concept of Monopoly and the Measurement of Monopoly Power A.P. Lerner I (1933-4) 157-75

2. On the Economic Theory of Socialism: Part I O. Lange Iv (1936-7) 53-71

3. A Note on Socialist Economics A. P. Lerner IV (1936-7) 72-6

4. Mr. Lerner's " Note on Socialist Economics" IV (1936-7) 143-4

vii

5. A Note on Welfare Propositions in Economics T. de Scitovszky 46 IX (1941-2) 77-88

6. A Reconsideration of the Theory of Tariffs T. de Scitovszky 58 IX (1941-2) 89-110

7. On Optimum Tariff Structures J. de V. Graaff 80 XVII (1949-50) 47-59

8. The Cost of a Family A. M. Henderson 93 XVII (1949-50) 127-48

9. Optimum Tariffs and Retaliation H. G. Johnson 115 XXI (1953-4) 142-53

10. Myopia and Inconsistency in Dynamic Utility Maximization $\quad R$. H. Strotz 128 XXIII (1955-6) 165-80

11. The General Theory of Second Best $\quad R$. G. Lipsey and K. Lancaster 144 xxIV (1956-7) 11-32

12. Tariffs, Retaliation, and the Elasticity of Demand for Imports W. M. Gorman 167 XXV (1957-8) 133-62

13. Comments on "The General Theory of Second Best " M. McManus XXVI (1958-9) 209-24

14. McManus on Second Best K. Lancaster and R. G. Lipsey XXVI (1958-9) 225-6

15. The Analogy between Atemporal and Intertemporal Theories of Resource Allocation E. Malinvaud XXVIII (1960-1) 143-60

16. Paths of Economic Growth that are Optimal with Regard only to Final States: A Turnpike Theorem R. Radner XXVIII (1960-1) 98-104

17. The Social Optimum in the Presence of Monopoly and Taxation H. A.J.
Green

17. The Social Optimum in the Presence of Monopoly and Taxation H. A.J.
Green XxIx (1961-2) 66-78

18. Choosing an Investment Program among Interdependent Projects S. Reiter 253 XXx (1963) 32-6

19. The Role of Securities in the Optimal Allocation of Risk-bearing $K . J$. Arrow XXXI (1964) 91-6 
20. A Note on Democratic Decision and the Existence of Choice Sets $P$. $K$. Pattanaik XXXv (1968) 1-9

21. Planning without Prices G. M. Heal XXXVI (1969) 347-62 


\section{Introduction}

Many of the most important contributions to modern welfare economics were first published in the Review of Economic Studies. This volume presents a selection of them. There are obvious omissions. Inevitably, crucial contributions have appeared in books and in other journals; and even among important articles published by the Review, many have had to be omitted because of shortage of space or for other reasons. An attempt has been made by means of footnote references to some of this omitted material to indicate the context in which the articles here reprinted were written; but it must be emphasised that this is not intended to constitute even the most fragmentary of bibliographies, and that the omission of such a reference in no way implies any lack of quality or importance. Nevertheless, both the articles included and those referred to include their authors' own reference lists, which together constitute, if not a bibliography, at least a formidable reading list!

The reader may be surprised at the diversity of the articles in this volume, and sometimes at their apparent lack of welfare content. This arises from our definition of welfare economics, which is a very broad one. At one end of the spectrum of possible definitions, one might treat welfare economics as an exercise in deriving the most general (conditional) policy recommendations from a minimum of value judgements, eschewing empirical facts and (so far as possible) positive economic analysis. Such an approach is likely to be frustrating, and may be responsible for the view held in some quarters that welfare economics is sterile.

In contrast, we regard welfare economics as concerned with making policy recommendations applicable in the world of economic affairs and believe that, while it must make clear the value judgements utilised and, indeed, use as few as possible, it must also draw heavily on positive and empirical analysis; we shall even include exercises in positive analysis if they are directly and importantly relevant to the derivation of policy recommendations. With such a definition, it is not surprising that welfare economics should seem a vast and diverse subject. Indeed, it is not (in its present state) a monolithic subject, but rather a large area from which various authors have selected various problems, attacking them with differing methods and at differing levels of abstraction. The unity of the subject is thus to be sought in certain themes which recur in different combinations in different articles. We try, in this introduction, to trace these interwoven themes through the various articles reprinted here.

It is primarily for this reason that the articles are reprinted in simple chronological order: no attempt at grouping by subject could do justice to the complexity of the interrelationships. It is also helpful to preserve the chronological sequence in a branch of economics which, perhaps more than any other, has developed by a dialectical process. 
The most thoroughly worked-out general problem in welfare economics is the relationship of a social optimum, a Pareto optimum and the " marginal conditions ". 1 Lerner (paper 1) en passant clarifies the concept of Pareto optimality and its necessity (on weak conditions) for a social optimum, as well as the sufficiency (on strong conditions) for Pareto optimality of the equality of price and marginal cost. It was not until many years later that these relationships were generally understood within the profession.

A more fundamental concept than Pareto optimality is that of Pareto dominance. We should say that an allocation $a$ of goods to all individuals " Pareto dominates " an allocation $b(a D b)$ if $a$ makes no individual worse off and at least one individual better off than $b$. (We shall follow general usage in saying that an individual is better off with a bundle of goods $x$ than with a bundle $y$ if he prefers $x$ to $y$, and that he prefers $x$ to $y$ if he chooses $x$ when $y$ is available. This, of course, begs several questions, for we know that most men sometimes make choices they regret, and that some men are arrogant enough to say that others would be better off with $y$ though they preferred $x$. However, glossing over these difficulties permits us to concentrate on others, formidable enough in themselves.) It is at once clear that Pareto-optimal allocations are those not Pareto-dominated by any possible allocation-indeed, much confusion might have been avoided if they had been christened "Pareto-undominated ", but the term "Pareto optimum " is by now too widely accepted for the change to be useful.

Pareto dominance is a relationship that can obtain between two allocations, neither of which is a Pareto optimum. Nevertheless, it is sadly difficult to find applications for it in the real world, and accordingly attempts were made to construct weaker but more widely applicable relationships by means of " compensation tests". Thus the relationship $a K b$ was proposed, ${ }^{2}$ which would hold if, although some individuals were worse off at $a$ than $b$, they could be compensated by those better off, so that a new allocation $a^{\prime}$ could be reached from $a$ by redistribution, such that $a^{\prime} D b$. De Scitovszky ${ }^{3}$ (papers 5 and 6) shows that allocations $a$ and $b$ can be found, such that simultaneously $a K b$ and $b K a$. He then proposes the stricter relation $a S b$, which would hold only if $a K b$ and not $b K a$.

In the course of his analysis, Scitovsky introduces the famous Scitovsky aggregate indifference curves. Graaff (paper 7), however, following Samuelson, uses utility possibility curves to show that Scitovsky's own criterion is insufficient to ensure that the utility possibility curves corresponding to two allocations do not intersect, which is necessary if paradoxes of the kind discussed in the previous paragraph are to be avoided. In the long run, though, the Scitovsky aggregate indifference curves have proved crucial in the analysis of Pareto optimality, where they form the boundaries of the aggregate preference sets corresponding to given allocations. ${ }^{4}$

Even if one accepts the weak assumption that a social optimum must be Pareto optimal, one is left with the task of choosing the social optimum from among a probably

${ }^{1}$ See, for instance, J. Quirk and R. Saposnik, Introduction to General Equilibrium Theory and Welfare Economics (McGraw-Hill, New York, 1968).

"See, for instance, N. Kaldor, "Welfare Propositions of Economics and Interpersonal Comparisons of Utility," Economic Journal (1939).

${ }^{3}$ Now known as T. Scitovsky.

${ }^{4}$ See T. C. Koopmans, Three Essays in the State of Economic Science (McGraw-Hill, New York, 1957), Essay I. 
infinite set of Pareto optima. This is easily (and commonly) done by some quite arbitrary rule, but the quest for a non-arbitrary method of choosing has created a difficult and highly abstract subject-the theory of social choice-which may be regarded as part of welfare economics, or of political science, or of both.

It may roughly be regarded as the investigation of procedures for translating individual preferences into social decisions, considered at a high enough level of generality to include both voting systems and market mechanisms as particular instances. The subject achieved prominence through Arrow's gloriously misnamed General Possibility Theorem, ${ }^{1}$ which shows that, if one lists in advance certain properties which most people would wish such a procedure to have, no procedure with these properties exists! A considerable literature has since been devoted to attempts to construct other lists of desiderata, not substantially less appealing but such that procedures satisfying them exist. The Review has not published much of this literature, but Pattanaik (paper 20) is a recent and important paper in this tradition which offers the reader both a high-quality sample of the literature and a starting-point for further reading in the subject.

\section{II}

So far we have discussed welfare economics-in particular the optimal allocation of resources-under conditions of perfect knowledge and a purely static economy. Maintaining the assumption of perfect knowledge, it might seem easy to make the analysis dynamic by simply " dating " the commodities, so that the same commodity at $T$ different times could be treated formally as $T$ distinct commodities. Unfortunately, a dynamic model introduces new and formidable difficulties, as Malinvaud (paper 15) points out, at the same time discussing some of the ways of dealing with them.

Strotz (paper 10) investigates a difficulty peculiar to the dynamic formulation-that consumers who are in some sense rational in their choices at a given time may very well not be so in their intertemporal choices. This is not the simple problem of time discount, which had long been allowed for. It is rather an unforeseen difficulty in the way in which time discount was allowed for. Economists, whether by convention or for mathematical convenience, had used an exponential time-discount function, which has the happy consequence of producing consistency in planning over time; that is, given a discounted utility-maximising plan made at one date and followed until a later date, any recalculation at the later date will leave the remainder of the plan unchanged. This obviously depends on perfect foresight, but much less obviously on the apparently innocuous choice of an exponential discount function. Strotz shows that this consistency only obtains with this particular function which, although mathematically convenient and not implausible, is arbitrary. Strotz, indeed, seems to argue that it is the right discount function solely because it is the only one that yields consistency. Little has been done ${ }^{2}$ to overcome this singularly nasty obstacle to developing a dynamic welfare economics.

The problems of welfare economics given perfect knowledge are so great that one hesitates to open the Pandora's Box of uncertainty, but it is an unpleasant task which

${ }^{1}$ K. J. Arrow, Social Choice and Individual Values (Wiley, New York, 1951).

${ }^{2}$ See, however, R. A. Pollack, “ Consistent Planning”, Review of Economic Studies (1968). 
cannot be shirked. Arrow (paper 19) ${ }^{1}$ introduces the concepts of " states of nature ", of " claims" contingent on these states of nature, and of markets in these "contingent claims". These concepts have formed the basis for developing a theory of the optimal allocation of resources under uncertainty, which may well be regarded as one of the current " frontiers of knowledge ". ${ }^{2}$

\section{III}

The concepts discussed in Section II are invaluable in analysing economic welfare at a highly theoretical level, but their applicability is another matter. It is useful to know that Pareto optimality is necessary but not sufficient for a social optimum; but the likelihood of finding a Pareto optimum in real life is small. Pareto dominance seems more applicable, but the chances of moving from one allocation to another which Pareto dominates it decline rapidly with the number of individuals in the community. Similarly, it would be difficult in practice to determine whether two utility possibility surfaces (drawn in a realistically large number of dimensions) intersect or not. Accordingly, many economists have, while keeping this theoretical structure in mind, approached particular problems by considering first their particular characteristics.

Lerner (paper 1) begins his analysis of the welfare effects of monopoly by separating monopoly rents from the misallocation of resources caused by monopoly pricing. Monopoly legislation often has been (and still frequently is) inspired by a desire to limit monopoly rents; yet the latter constitute a problem which has far less to do specifically with monopoly than with the general distribution of income. In contrast, the social loss through misallocation of resources due to monopoly pricing is, as a first approximation, a proper target for monopoly legislation. That this misallocation can be accurately dealt with only in the context of the allocation of resources in the whole economy, and that propositions about allocation must be qualified by value judgements about the associated distribution of incomes, are recurrent themes in the literature.

Lerner concludes by offering a measure of the social loss due to monopoly pricing, and if we find it not entirely satisfactory, we must remember that two decades passed before attempts to measure such losses became fashionable and better measures were evolved. $^{3}$

A related but more complex problem, on which the literature is so vast that it could occupy at least one volume by itself, is that of the optimum tariff. As expounded by Scitovsky (paper 6), it consists in the fact that, while the "world as a whole" will be better off under free trade, any individual country can, in general, increase its welfare by imposing an import duty. This result is strengthened and generalised by Graaff (paper 7). Scitovsky then considers " retaliation" by other countries and concludes that (with

1 Although this paper was first published in English in 1964, it had been presented in French as early as 1952 .

${ }^{2}$ For further development, the reader should see G. Debreu, Theory of Value (Wiley, New York, 1959), and for a recent survey, R. Radner, “Problems in the Theory of Markets under Uncertainty", American Economic Review, Papers and Proceedings (1970).

${ }^{3}$ For instance, G. Debreu, " The Coefficient of Resource Utilisation ", Econometrica (1951); A. C. Harberger, "Monopoly and Resource Allocation", American Economic Review, Papers and Proceedings (1954). 
certain qualifications) eventually each country individually will be worse off than under free trade. We thus have a classic welfare problem, where co-operation can make all parties better off than if each follows his own self-interest (narrowly defined, of course!).

However, it would be surprising if so complex a problem could really be formulated with such classic simplicity, and Johnson (paper 9), studying the mechanism of retaliation, shows that it can happen that a country is better off even after a tariff war. If this happens, it calls into question the sense in which the " world as a whole " is better off under free trade and, naturally, the interest of the country in question in co-operating to secure free trade. In the terminology of Section II, although the free trade position remains a Pareto optimum, it no longer Pareto dominates the result of a tariff war.

Gorman (paper 12) extends Johnson's analysis to produce a large class of cases in which a country may be better off after a tariff war, but his great contribution is to derive numerical conditions for this to happen, as well as numerical estimates of the effect of the tariff war on the volume of trade. It must already be clear to the reader that numerical estimates are lamentably rare in the literature, and to derive them in so complex a problem is a signal achievement.

Henderson (paper 8), too, provides an object lesson in the detailed calculation (based in his case on empirical data) that is a prerequisite of policy recommendation. He considers the different ends which the system of family allowances, income-tax allowances for children, and food subsidies might be designed to achieve, and the extent to which, in the immediate postwar period, they succeeded. The actual statistics, and the calculations based on them, are of course dated, but they still serve as a model for the calculations that should be performed.

It might be thought that the discussion of the ends themselves was also obsolete, but ironically, although some of the premises have changed, the analysis remains directly relevant to a problem which, although little discussed in the academic literature, is probably even more important now than when Henderson wrote. The most obvious objective-the prevention of poverty-remains unchanged, but whereas in 1950 this merely diverged from that of preventing a declining population by relieving parents of the "cost " of having children, it may now be seen as directly opposed to the need to prevent a " population explosion". (Of course, Henderson's use of financial costs is inadequate in that it ignores both the utility of having children and the disutility of caring for them, and the former may exceed the latter by so much as to constitute a major factor in the problem.)

Henderson also notes the possible objective of increasing the proportion of children coming from middle-class families. He does not attempt the detailed analysis that would be needed to justify such a quasi-eugenic policy, but merely points out that such an analysis might be based on the hypothesis that differential fertility rates are causing a secular decline in intelligence. As this hypothesis is now very doubtful, one might think that the possible objective could be ignored; but, while the debate on the relative importance of " nature " and " nurture" has raged inconclusively, it has been relatively firmly established that, by whatever means, the " social class " of a child's parent has a marked effect on its academic achievement. Thus, for Henderson, the distinction between " nature " and " nurture" is irrelevant. So far as the effect is hereditary, an analysis would be based on a desire to increase the proportion of naturally gifted children - so far as it is due to favourable family backgrounds, on a desire to give more children the benefit of such backgrounds. 
IV

A great part of early welfare economics-not represented in this volume since it was published before the Review came into being - was what Hicks ${ }^{1}$ has termed " partial welfare analysis ". It concerned the correct setting of the price for a particular commodity and whether or not to introduce a new commodity, and was based on the assumption of measurable utility, which implied that the gain or loss in utility to each individual could be measured, and that these gains and losses could be added so as to determine the aggregate net gain or loss for the community. When measurable utility fell into disrepute, so too did the welfare analysis based on it.

However, determined attempts were made to salvage so valuable a branch of economics, and in a series of articles Hicks and Henderson ${ }^{2}$ showed that consumers' surplus (and hence individual net gains and losses) could be measured in money terms. But, whereas the measurable utilities of individuals were additive (interpersonally comparable), no such process could be performed with gains and losses measured in money terms. The economist was then thrown back on Pareto dominance and driven to the various unsuccessful attempts, discussed in Section I, to extend the concept by way of compensation tests. But if the compensation tests yielded paradoxes in some cases at the abstract level of pure theory, they also yielded useful recommendations at a " roughand-ready " level in many practical cases. The rough-and-ready arguments ran something like this: "If the gains are large compared with the losses, and no substantial worsening in the distribution of welfare is involved (implicitly introducing a rough-andready interpersonal comparison of utilities), then..." Thus, in a pragmatic way, partial welfare economics became once more a subject prolific of practical policy recommendations. It was particularly important in two fields-the setting of prices in nationalised industries, which must perforce, directly or indirectly, be done by the government, and decisions on whether to undertake a new investment project, where the calculations suggested by Hicks ${ }^{3}$ have been popularised under the title of " cost-benefit analysis ". ${ }^{4}$ It was on this busy, pragmatic activity that Lipsey and Lancaster (paper 11) launched their famous attack.

They argue that " if one of the Paretian optimum conditions cannot be fulfilled, a second best optimum is achieved only by departing from all other ${ }^{5}$ optimum conditions ... in general, nothing can be said about the direction or the magnitude of the secondary departures from optimum conditions made necessary by the original nonfulfilment of one condition ". They demonstrate the relevance of this negative proposition to a variety of economic problems and assert " the futility of " piecemeal welfare economics"". McManus (paper 13) strengthens and clarifies their arguments in

1 J. R. Hicks, “"The Rehabilitation of Consumers' Surplus ”, Review of Economic Studies (1941).

${ }^{2}$ See J. R. Hicks, A Revision of Demand Theory (Clarendon Press, Oxford, 1956), Chapter X:

3 I. R. Hicks, “ The Rehabilitation of Consumers' Surplus ", Review of Economic Studies (1941), pp. 115-16.

${ }^{4}$ See A. R. Prest and R. Turvey, “ Cost-Benefit Analysis: A Survey ”, Economic Journal (1965).

5 This very strong statement should, I think, be read as qualified by the words " in general"; occurring in the previous paragraph but one. However, recent interest has centred on cases where the violation of one condition can leave a large class of optimal conditions unchanged. See, for instance, P. A. Diamond and J. A. Mirrlees, "Optimal Taxation and Public Production ", American Economic Review (March and June 1971), and for an early precursor, M. Boiteux, "Sur la gestation des monopoles publics astreints à l'équilibre bugdétaire ", Econometrica (1956.) 
important respects, including the role of the numéraire, which he shows to introduce an additional (implicit) constraint.

It should perhaps be said that economists were aware that departures from optimal conditions elsewhere in the economy affected the particular partial welfare analysis they were conducting, but thought they could make appropriate (if approximate) allowance for this. The devastating part of the proposition was that " in general, nothing can be said about the direction or the magnitude of the secondary departures ". Fortunately, Green (paper 17) shows that while all this is true, it is also misleading: nothing in general can be said, but in particular cases quite a lot can usefully be said. He takes the important particular case of setting prices for the products of an arbitrary number of nationalised industries, the prices of an arbitrary number of other commodities being assumed fixed at various non-optimal levels. He shows that, under certain conditions, bounds can be placed on the optimal ratio of price to marginal cost for the products of the nationalised industries and moreover that, leaving aside the separate problem of the divergence of marginal social and marginal private costs, the information required to determine whether the conditions are satisfied and to calculate the bounds is relatively modest.

Thus the "second best" controversy serves to place pragmatic partial welfare analysis on a firmer footing than before. It also provides a fine illustration of how the pursuit of unattainable generality can lead to misleadingly negative conclusions, which can be avoided by the injection of positive analysis and factual information.

\section{V}

Lange (papers 2 and 4) and Lerner (paper 3), in discussing the allocation of resources in a socialist economy, make the first systematic attack on perhaps the biggest issue in welfare economics-the analysis of alternative mechanisms for allocating resources. They show that a socialist economy can in principle, using an iterative planning process and accounting prices, approach the optimal allocation of resources in a way closely analogous to that of a free market economy, using markets and market prices. This opens the way for more important comparisons, like that between the working of actual planning bureaucracies and of institutionally imperfect markets. Unfortunately, little work has been done on this particular problem and, indeed, political prejudice has too often led to the comparison of a theoretically perfect planning system with an imperfect market system, or of an idealised system of perfect markets with an actual bureaucracy.

However, much theoretical work has been done on the convergence properties of various allocation processes, including the two mentioned above. Heal (paper 21) is particularly concerned with whether the allocation is feasible throughout the allocation process, and whether (in an appropriate sense) the convergence is monotonic. In these respects, and in the amount of information to be exchanged and processed, he compares his proposed technique with two of the outstanding techniques developed in the thirty years since the articles by Lange and Lerner. It is noteworthy that Heal does not use accounting prices to mimic the market, but rather a system of quantity allocations which has the advantage of conforming to the practice of many actual planning bureaucracies; however, the fact that his " firms " must report marginal productivities to the planning bureaucracy suggests that it is difficult completely to eliminate the exchange of " price-like" information. 
Heal also discusses-but only partially solves-the problems posed by non-convex production possibility sets. His technique converges to a local maximum, but if there is more than one local maximum, it need not converge to the largest of these. Multiple local maxima occur in practice as a consequence, inter alia, of large indivisible investment projects. The techniques used for evaluating investment projects separately rest on an assumption of independence which may be approximately valid if the projects are small enough, but is most unlikely to hold for large projects. This means that instead of evaluating $n$ investment projects, we have to evaluate $2^{n}$ investment programmes (that is, combinations of projects), and while this number is finite if $n$ is finite, it is likely to be very much larger. This is the problem considered by Reiter (paper 18).

Reiter assumes that the value of any programme can be simply computed and that there exists a simple algorithm for moving from a given programme to a "neighbouring " programme (suitably defined) with a higher value. Such an algorithm will stop when no neighbouring programme with a higher value exists; it will usually stop after a small number of steps and at a programme which is not optimal. However, the simplicity of the calculations and the small number of steps make it feasible to repeat the process many times on a computer. Reiter quotes the results of doing so, starting each time from a randomly chosen programme, and the probability of reaching the optimal programme with relatively simple calculations is impressively high.

In the real world, of course, calculating the value of any investment programme involves maximising with respect to the continuous variables while assuming that particular programme to be implemented $\rightarrow$ a far from simple calculation. Thus we must combine the Reiter problem for large interdependent investment projects with the Heal problem of finding a local maximum-problems reasonably soluble separately but massively difficult in combination!

At this point, we must note the relevance to these problems, large enough in themselves, of the difficulties raised by Malivaud (paper 15), Strotz (paper 10) and Arrow (paper 19). But planning in a dynamic setting is the subject of a vast literature on "optimum growth", which is largely omitted here since a symposium from the Review has already been published on the subject. ${ }^{1}$ However, Radner (paper 16) presents a particularly short and clear version of the famous " Turnpike Theorem ". ${ }^{2}$ Its relevance to welfare economies lies in the proposition that the dynamic path designed to maximise a utility function of the stocks of all commodities at a given (sufficiently distant) future date is remarkably insensitive to the weights attached by the utility function to the different commodities. This relevance is limited, however, not only by certain strong assumptions in the model used, but more obviously by the fact that interim consumption, although included as a necessary part of the productive process, is absent from the maximand. Subsequent work has attempted, ${ }^{3}$ with partial success, to remedy this defect; but, despite its flavour of " jam tomorrow", the Turnpike Theorem cannot be ignored.

\section{J. FARRELL}

\footnotetext{
${ }^{1}$ Problems in the Theory of Optimal Accumulation: A Collection from the Review of Economic Studies (Oliver \& Boyd, Edinburgh, 1967).

${ }^{2}$ For a broader study, see L. W. McKenzie, " Capital Accumulation Optimal in the Final State ", in Contributions to the von Neumann Growth Model (Springer Verlag, Vienna, 1971).

${ }^{3}$ See, for instance, J. Tsukui, "The Consumption and the Output Turnpike Theorems in a von Neumann Type of Model: A Finite Term Problem ", Review of Economic Studies (1967).
} 
Note on numbering of pages

The articles in this volume have been renumbered to run consecutively. References to pages within the same article have been changed to the new numbering. References to other articles also included in this volume have been reproduced in their original form, but the page reference in terms of the new numbering has been added in square brackets. 